\title{
MPRA
}

Munich Personal RePEc Archive

\section{Analysis of Herd Behavior Using Quantile Regression: Evidence from Karachi Stock Exchange (KSE)}

Malik, Saif Ullah and Elahi, Muhammad Ather

1 April 2014

Online at https://mpra.ub.uni-muenchen.de/55322/

MPRA Paper No. 55322, posted 16 Apr 2014 04:02 UTC 


\title{
Analysis of Herd Behavior Using Quantile Regression: Evidence from Karachi Stock Exchange (KSE)
}

\author{
Saif Ullah Malik ${ }^{1}$ \\ saifullah_142@yahoo.com \\ Dr. Muhammad Ather Elahi ${ }^{2}$ \\ matherelahi@gmail.com
}

\begin{abstract}
The objectives of this paper are to explore the herd behavior in the Karachi Stock Exchange (KSE) by using Ordinary Least Square (OLS) and Quantile Regression analysis for normal as well as bullish (up) and bearish(down) market conditions. Greed stimulates people to make increasingly risky investments and therefore investors tend to follow one another blindly and ignore rational analysis. Herd behavior can be defined as when investor ignore available information and follow other investors during investment decision making. The results shows the existence of herding in KSE during normal and both bullish and bearish markets. The analysis of herding is important because the mistakes of investors at the collective level may result in an inefficient pricing of assets. The results of this paper may help to avoid psychological traps linked with investing and are important for both investors and those regulatory institutions responsible for securing the strength of financial systems.
\end{abstract}

JEL: G02, C21, Key Words: Herd Behavior, Greed, Quantile Regression, Karachi Stock Exchange (KSE)

1. Saif Ullah Malik is Ph.D Scholar at SZABIST Karachi

2. Dr. Muhammad Ather Elahi is Assistant Professor at Institute of Business Administration (IBA) Karachi

All errors and omissions are the author's own and do not constitute those of the institutes. 


\section{Introduction}

Greed stimulates hope for a rapid growth in consumption and a fast leap to a higher standard of living. Due to greed, investors fail to properly diversify their investments and accept unnecessary high risk in the hope of gaining huge profits. This often leads to gambling by investors on investments in selected securities. Greed stimulates people to make increasingly risky investments and investors tend to follow one another blindly and ignore rational analysis. Herd behavior concept can be defined as when investor ignore available information and follow other investors during investment decision making.

Herd behavior can be explained as the behavior of investors trading in the same direction in a market and following other investors. Lakonishok, Shleifer, and Vishny (1992) defined herding as "buying (selling) simultaneously the same stocks as others buy (sell)." Herding can be categorized into two types i.e. spurious herding (unintentional herding) and intentional herding. Spurious herding is defined as "the phenomenon where groups facing similar decision problems and information sets, take similar decisions". This spurious herding arises due to fundamentals; for example, a sudden rise in interest rates may lead to simultaneous sale of the stocks of highly leveraged companies by all investors. On the other hand, intentional herding - when groups intentionally follow others due to informational cascade or reputational reasons, is inefficient and usually characterized by financial fragility (Bikhchandani \& Sharma, 2001). An important question is why investors knowingly indulge in such inefficient and unconventional behavior?

There are numerous reasons for making decisions by following others (herd behavior). First, some investors (usually big ones) may have better knowledge of the market and following their actions may lead to abnormal profits with less effort (rational herding). Second, compensation schemes may be designed in such a way that herding pays back to the employees (reputational herding). Third, herding is an intrinsic preference for conformity (intentional 
herding) by the individual investor (Bikhchandani \& Sharma, 2001). Herding literature showed that individual investors trade on sentiments due to ignorance and less information (Nofsinger \& Sias, 1999). Investors may herd due to lack of information and knowledge about the business of individual firms (Chen, Rui, \& Xu, 2004). In Global Press Freedom Rankings 2011 Pakistan is ranked at number 134 indicating that in Pakistan access to information is very poor.

Theory suggests that individual investors may engage in herding due to irrational behavior while institutional investors engaged in herding due to agency problems. However, Individual small investors are more worried about the future of the stock market than big institutional investors and the former has less holding power. Therefore, measuring individual investor behavior is very important. Individual investors have many other problems like less holding power and absence of technical expertise. These factors when coupled with greed convince investors to follow big investors or invest blindly. This behavior of investors is the main cause of herding in stock markets.

Pakistan has three Stock Exchanges in the country; one each at Karachi, Islamabad and Lahore. However, the Karachi Stock Exchange is the main stock exchange of Pakistan which accounts for approximately 92 per cent traded volumeof the country (Economic Survey of Pakistan, 2011-2012). Karachi Stock Exchange (KSE) is considered as one of the leading emerging stock markets in the world and is a target of many fund managers and foreign investors. Typically, the market is dominated by few large investors (big players) and many small investors. During the last ten years the Karachi Stock Exchange (KSE) has shown volatility and variations. The market experienced two crises that throw doubts on the fairness of the market operations. More specifically, the stock market experienced a boomstarting from 2003 till March 2008. During this period many investors earned phenomenal average returns and 
high risk. Then, the market crashed in 2008 that dried up volume in KSE. There were many grievances of small investors in both crashes. Therefore, it is important to study their motivation and their position in up and down signs of the market.

The profits of KSE have contracted extra ordinarily by over 93 per cent since the 2008 crash. Many market participants believed that this is due to fleeing of small investors from the market (Dilawar, 2011). Though small investors blame big investors for manipulating the market, it is basically greed and absence of technical expertise that played a role in the huge losses. Stock market crashes are driven by panic after the burst of speculative stock market bubbles. There are several economic and social reasons for the formation of such bubbles. Typically the investors' greed, excessive economic optimism, unnecessary use of leverage by market participants, less holding powers of individuals and lack of technical expertise are the main factors contributing to stock price bubbles. These bubbles burst when adverse external economic events coupled with following other investors blindly create a positive feedback loop and some investors start to sell in panic. An important cause of these crashes is less holding power of individual investor as most of the small investors depend on badla or margin financing from brokers. Badla financing is one of the causes of instability in the Karachi Stock Exchange (Rashid \& Husain, 2009). Due to Badla financing or margin financing, investors have less holding power and they are bound to sell shares. These factors compel investors to follow the big investors.

This paper is first of its kind in Pakistan and attempts to find existence of herd behavior in the Karachi Stock Exchange (KSE). It also attempts to find the difference in herding behavior under up and down markets. This analysis helps to find the answer to an important question viz. whether herding behavior during abnormal market conditions differs from the herding behavior 
under normal market conditions. Further, to that this study also uses Quantile regression analysis for both normal market conditions and under up and down market. This technique is rarely used in Pakistan. It helps us to find herding behaviour at different Quantiles of return distribution. QuantileRegression $(\mathrm{QR})$ enables the examination of effects in different points of market return distribution and can be used to obtain estimates for herding in the tails of market return distribution. Theory suggests that herding will be more at the lower tail of market return or at extreme market conditions. This paper also discuses difference in results by using ordinary least squared method and Quantile regression analysis. The following are the main research objectives of this study.

1. To identify the existence of herding behavior in the Karachi Stock Exchange (KSE).

2. To distinguish the herd behavior under bullish (up) and bearish (down) markets in the Karachi Stock Exchange (KSE).

3. To identify the existence of herding behavior in different quantiles in the Karachi Stock Exchange (KSE).

4. To suggest remedial measures to avoid future occurrence of herd behavior in the Karachi Stock Exchange (KSE).

This study will answer following important questions:-

1. Does herd behavior exist in the Karachi Stock Exchange?

2. Is herding behaviour under bullish (up) and bearish (down)market conditions different from that during normal market condition?

3. Does the herding behaviour vary at different quantiles of the stock market return?

This paper will academically and practically benefit investors and policy makers in understanding herding behavior in the Karachi Stock Exchange (KSE). The causes of investor 
herding are important for both policy making and the efficient working of stock markets (Bikhchandani \& Sharma, 2001). This paper makes an attempt to study individual investor behavior in Karachi Stock Exchange (KSE). Analysis of the behavior of individual investors is important as investments are very crucial for any country. Pakistan is making every effort to enhance investment in the country. It is necessary to study investor's behavior before making such efforts to enhance investments. The current situation of terrorism and political uncertainty are playing a crucial role in investor's behavior about investment. The main focus of the study is on small investors, trading in Karachi Stock Exchange (KSE). The analysis of herding is important because the mistakes of investors at the collective level may result in an inefficient pricing of assets. The results of this study may help avoid psychological traps linked with investing and are important for both investors and regulatory institutions responsible for securing the strength of financial systems. This paper also suggests some remedial measures to avoid herd behavior in the Karachi Stock Exchange (KSE).

\section{Literature Review}

In simple terms, herd behavior is behavior of the individual investor to blindly follow other investors. Banerjee (1992) defined herd behavior as "people will be doing what others are doing rather than using their own information". Grinblatt, Titman, and Wermers (1995) defined herding as "the extent to which the group either predominantly buys or predominantly sells the same stock at the same time". Sias (2004) defined as"following each other into (or out of) the same securities over some period of time". Theories of herding can be categorized into two subgroups i.e. intentional ('true') herding and unintentional ('spurious') herding. Intentional or true herding results from copying or following the behavior of other investors while unintentional ('spurious') herding exists due to changes in fundamentals. Intentional herding may further be 
divided into informational cascades or reputational herding. Informational cascades occur due to observation of investment decision of other investors instead of using own private information by investor. Reputational herding occurs due to reputational concerns of manager instead of return of investors[(Bikhchandani \& Sharma, 2001);(Holmes, Kallinterakis, \& Ferreira, 2011); (Walter and Weber (2006)].

Unintentional (spurious) type of herding is based on characteristic trading e.g. momentum or buying winner stock [(Lakonishok, Shleifer, \& Vishny, 1992); (Grinblatt, Titman, \& Wermers, 1995)], contrarian (buying loser stock), buying value stock, growth stock, small stock and large stock (Holmes, Kallinterakis, \& Ferreira, 2011). This type of herd behavior is irrational as, according to the efficient markets hypothesis, price of stock should reflect all available information. This behavior can deteriorate price movements and add to volatility (Bikhchandani \& Sharma, 2001). Momentum (buying past winner) in stock prices may result in overpricing which ultimately results in stock market volatility (Walter \& Weber, 2006).

Intentional herding may further be classified into two type's i.e. informational cascades and reputational herding. The concept of informational cascades is that one investor observes other investor's decisions and adds useful information up to a certain level. For example, an investor with negative information can purchase a particular stock if he observes that other investors are also purchasing this stock (Devenow \& Welch, 1996). This is due to the belief that investors think that other investors may have better information (Bikhchandani \& Sharma, 2001). In informational cascades model, individuals quickly join one action on the basis of very limited information. The social equilibrium may radically shift if anyone suggests that a different option is optimal (Bikhchandani, Hirshleifer, \& Welch, 1992). Some investors follow other investors as a solution to avoid informational cascades (uncertainty in stock market). In more volatile stock 
markets like Karachi Stock Exchange (KSE), some investors prefer to follow other investors due to the high risk involved in investment decisions.

The follower of this belief believed that the uneducated and inexperienced investors should follow market gurus or educated and experienced investors. They should take advice from experienced investors, because if they use their own information it will result in less benefit and more cost. Therefore, stock prices deviate from fundamentals due to herding behavior of investors (Amirat \& Bouri, 2009). When the accuracy of the investor's information is not common knowledge, an informational herd behavior may be occurred which results in overpricing of stock prices (Bikhchandani \& Sharma, 2001). This overpricing coupled with large buying from some investors cause prices of some stock to increase unrealistically which ultimately results in a sharp fall in prices. These fluctuations are not due to fundamentals or any relevant information but mainly due to the existence of herding of investors (Amirat \& Bouri, 2009). However, when herding ends after inclusion of the information in prices, the stock market crashes due to unavailability of investors of over priced stock.

Rational asset pricing model suggests that individual investors set their own risk level and trade on the basis of their own information. Therefore, return's dispersion is related to absolute market return under normal market conditions. But, investors ignore their own information and follow the market under high market movement. As a result, the difference between stock return and market return is reduced. Hence, there will be more chances of herding under market stress (Khoshsirat \& Salari, 2011). The uninformed investors try to follow the market and this information asymmetry may drive volatility (Wang, 1993). Uninformed investors buy in a bullish market and sell under bearish market conditions. Irrational traders wrongly believed that their own information was poorer than that of the market (Avery \& 
Zemsky, 1998). This belief creates a situation in which "the blind leads the blind" into a bubble. The price pressure took price away from the fundamental value. This price pressure makes clear that all the abnormal returns are not based on some specific information. When price is adjusted with little information, it creates a bubble. The traders considered that prices increase with an increase in asset value (Smith, 2011).

The herding is stronger when market expectations are similar. If the investor is confident about the direction of the market, herding will be strongest (Park, 2010). The same situation happened in Karachi Stock Exchange (KSE) before the stock market crash of March 2008. Chang, Cheng, and Khorana (2000) studied herding in five stocks markets including the developed markets (US, Hong Kong and Japan) and developing stock markets (South Korea and Taiwan). Empirical tests found that herding did not exist in US and Hong Kong during periods of extreme price movement. However, herding exist in South Korea and Taiwan stock market (Chang, Cheng, \& Khorana, 2000). Demirer, Kutan and Chen (2010) did not find herding evidences by using CSSD in Taiwanese Stock Market.

The results of previous studies suggested that herding is more common in declining market situations or when returns are low in the market [(Holmes, Kallinterakis, \& Ferreira, 2011); (Demirer, Kutan, \& Chen, 2010)]. On the other hand, Szyszka (2010) contradicted these findings and claimed that during the high market, investors decide on the basis of past prices and other investors behavior instead of fundamentals. Investors usually expect increase in prices but asset is already highly priced. Herding also exist due to information cascade even if all investors take rational decision (Szyszka, 2010). Economo, Kostakis, and Philippas (2010) studied herding behavior using daily data for the years 1998- 2008 under extreme market conditions in four stock markets i.e. Greek, Italian, Portuguese and Spanish stock markets. They used the Chang, Cheng 
and Khorana (2000) i.e. CCK measure for detecting herd behavior. Positive results of herding were found in the Portuguese, Italian and Greek stock markets but they were unable to find herding in the Spanish stock market (Economo, Kostakis, \& Philippas, 2010).

Chiang, Li,and Tan (2010) studied B-share investors of Chinese stock market by using Quantile regression technique and found positive results in the lower quantiles but did not find herding evidences in the higher quantiles. They also claimed that the least squares method ignored the information in the tail of return distribution. Mean is used as a measure of location in OLS (Ordinary Least Squares) method. However, the quantile regression method is used to calculate different curves, each against a different quantile of the variable under study. The quantile regression method shows relationships at different quantiles. This method also helps to reduce some of the statistical problems, like outliers (Barnes \& Hughes, 2002).

Hence, it is clear from the above literature that the fact that herding in the stock market has been studied in prior research in different financial markets. The results support the idea that when investors herd they tend to follow the market and, as a result, stock returns are close to the overall market return. This phenomenon is known as herd behavior which is an important concept in behavioral finance. The above cited literature also concludes that herding may be different under bullish (up) and bearish (down) due to fact that these conditions compel investors to follow other investors due to uncertainty.

\section{Research Methodology}

This study used daily data from the period 2003 to September 2013 to find evidence of herding behavior in the Karachi Stock Exchange (KSE). There were 638 firms listed on the Karachi Stock Exchange (KSE) as of December 31, 2013. However, during 2003-2013 many 
firms joined, merged or delisted. Hence, only those companies were selected which remained listed during the entire period i.e. 2003-13. A total of 261 companies were found eligible based on the criteria. Data of closing stock prices of these companies is collected from January 1, 2003 to September 30, 2013. The sample of 2659 observations is taken for each firm's daily return i.e. a total of 693,999 observations for all selected companies. The sample period has witnessed historic highs and lows and two stock market crashes i.e. the stock market crash of 2005 and 2008. This gives us the opportunity to analyze not only normal periods but also extreme market conditions. The sample period faced many ups and downs in Karachi Stock Exchange (KSE).

STATA 11 version is used to analyze data. The individual stock returns $\left(\mathrm{R}_{\mathrm{i}}\right)$ and overall market returns $\left(\mathrm{R}_{\mathrm{m}}\right)$ are calculated using these formula as $\mathrm{R}_{\mathrm{m}, \mathrm{t}}=\left(\mathrm{R}_{\mathrm{i}, t} / \mathrm{Rm}_{\mathrm{t}-1)}\right)^{-1}$ and $\mathrm{R}_{\mathrm{i}, \mathrm{t}}=\left(\mathrm{P}_{\mathrm{i}, t} / \mathrm{P}_{\mathrm{i}, \mathrm{t}-1}\right)$ - 1. For market return (Rm), the KSE - 100 index is used for the same period. The KSE-100 index is a market capitalization weighted index in which 34 companies are selected from each sector and remaining 66 companies are selected on the base of market capitalization. The KSE100 index is the main index in the Karachi Stock exchange (KSE). According to Economic Survey of Pakistan (2011-12), KSE-100 Index has contributed approximately 92\% of the overall capitalization of the market.

Empirically, detecting herd behavior is a difficult task due to unavailability of relevant data. Often, empirical data show only decisions taken by the investor and do not show the causal incentives attached. Amirat and Bouri (2009) divided the studies conducted so far on herd behavior into two groups. The first group is based on the individual investor's trading actions. Therefore, for this group detailed and clear information on the investor's trading activities is required. Lakonishok, Shleifer, and Vishny (1992) measure is an example of this group. On the other hand in the second group, the information about the combined trading actions of the 
investors is used as an indication of herd behavior. Cross-sectional stock price actions are used as a measure of herding behavior. The examples of such measures are Chang, Cheng, and Khorana (2000). This study follows the second group and uses cross-sectional stock price movements as a measure of herd behavior. First, data on individual trading is not available in most of the emerging stock markets. Second, the combined trading actions of the investor are common in the Karachi Stock Exchange (KSE). Many investors have little educational and technical expertise and most of them rely on a broker's advice or follow others advise or invest on rumors. Therefore, when they collectively sell, it creates a situation of market crash. Due to these reasons collective buying and selling behavior of investors should be studied.

All these methodologies are based on the rationale that when investors herd they tend to follow the market and, as a result, stock returns are close to the overall market return. Chang, Cheng, and Khorana (2000) developed a test of herd behavior dimensions and studied the overall market return and stock return dispersion. In their measure known as CCK measure, CSAD is calculated by comparing individual stock return with market return. Chang, Cheng, and Khorana (2000) model produced strong evidence of herding. They used cross sectional absolute deviation (CSAD) to detect herd behavior. They used this as a measure of return dispersion in the market. The equation is;

$$
\operatorname{CSAD}_{t}=\frac{1}{N} \sum_{i=\mathbf{1}}^{N}\left|R_{i, t}-\boldsymbol{R}_{m, t}\right|
$$

By using CSAD, Chang, Cheng, and Khorana, (2000) formed the herding equation as:

$$
\operatorname{CSAD}_{t}=\gamma_{0}+\gamma_{1}\left|\boldsymbol{R}_{m, t}\right|+\gamma_{2} \boldsymbol{R}_{m, t}^{2}+\varepsilon_{t} \cdots \ldots \ldots \text {.(ii) }
$$

Where the market return of the index is denoted as $\mathrm{R}_{\mathrm{m}, \mathrm{t}}$. The above equation (ii) enables us to detect herd behavior in Karachi Stock Exchange (KSE). A nonlinear term $R_{m i t}^{2}$ is added in 
the above equation. This shows that a nonlinear negative relationship exists between CSAD and $\mathrm{R}_{\mathrm{m}, \mathrm{t}}^{2}$ during periods of market stress. In the above equation, $\gamma_{1}$ will remain positively constant for both up and down market conditions. However, if $\gamma_{2}$ become significantly negative, it will be an indication of herding behavior. On the other hand, if $\gamma_{2}$ become insignificant or positive, it will show absence of herding behavior. This is due to fact that when investors herd they tend to follow the market and, as a result, stock returns are close to the overall market return.

In the above equation (ii), $\gamma_{1}$ will remain constant for both up and down market condition. To find herding behavior under bullish (up) and bearish (down) stock market conditions, above equation may be writtenas;

$$
\operatorname{CSAD}_{t}=\gamma_{0}+\gamma_{1}(1-D) R_{m, t}+\gamma_{2} D R_{m, t}+\gamma_{3}(1-D) R_{m, t}^{2}+\gamma_{4} D R_{m, t}^{2}+\varepsilon_{t}(\mathrm{iii})
$$

In the equation (iii) $\mathrm{D}$ is a proxy for market condition, $\mathrm{D}=1$ if $\mathrm{Rm}, \mathrm{t} \leqslant 0$, and $D=0$ if $\mathrm{Rm}$, $\mathrm{t} \geq 0$. According to Eq. (iii), the negative sign of $\gamma_{3}$ and $\gamma_{4}$ will indicate herding under bullish (up) and bearish (down) markets respectively. This is due to fact that when investors herd they tend to follow the market and, as a result, stock returns are close to the overall market return.

Quantile regression (QR) analysis is used to detect herding in the extreme quantiles of return distribution. There are three reasons to use Quantile Regression which is a semi parametric substitute of OLS. First, financial data usually does not have normality. Second, since the market stress models are common in the empirical financial herding literature, Quantile Regression is the best tool for analyzing extreme quantiles of return distribution. Third, Quantile Regression is strong in finding the presence of outliers (Koenker, 2004). Quantile regression (QR) enables the examination of effects in different points of market return distribution and can be used to obtain estimates for herding in the tails of market return distribution. When dispersion 
of returns decreases or increases at a decreasing rate and approach the market rate of return, this could be an indicator of herd behavior. By setting $t=0.1$ and $t=0.25$, quantile estimates for the extremely low returns can be obtained. Similarly, setting $t=0.75$ or $t=0.90$ produces quantile estimates for the extremely high returns.

Chiang, Li and Tan (2010) used quantile regression method in the Chinese stock market and claimed that quantile regression is stronger than OLS and as a result gives more efficient estimates due to its coverage of different quantiles. They also reported that results may be distorted due to excessive outliers created by news in financial markets (Chiang, Li, \& Tan, 2010). Due to its coverage of different quantiles, Barnes and Hughes (2002) reported that this method is the best to detect extreme values that have a skewed distribution or fat tails. Due to these reason, this method is superior to ordinary least squares regression.

\section{Results and discussion}

\subsection{Descriptive statistics}

Table 1 contains the descriptive statistics of variables under study to find out the temporal properties of the data. The variables under study i.e. Cross Section Absolute Deviation (CSAD), Stock Return (Ri), Market return (Rm) and Volume (V) are analyzed in terms of its mean for average return and standard deviation for volatility. The high value of mean clearly indicates higher variationsinvariables under study while the higher value of standard deviation may show higher volatility in variable under study. The mean for all variables are positive. The volume in 2008 is lowest due to the huge stock market crash and KSE reported that the daily volume of shares traded at KSE reduced to 80 million shares in 2011 from 620 million shares in 2008. The

detailed results are reported in table 1. The graphs of stock return (Ri), Market return (Rm), 
Volume and CSAD are shown below which indicate that stock return (Ri) and CSAD have more variations in years 2009-2013with less volumes. The detailed graph is shown in figure -2 .

Table 1: Descriptive Statistics

\begin{tabular}{llllll}
\hline Statistics & Obs. & Mean & Std. deviation & Skewness & Kurtosis \\
\hline CSAD & 693738 & 0.023273 & 0.044596 & 0 & 9.333278 \\
Stock Return (Ri) & 693738 & 0.001316 & 0.050327 & -0.89599 & 9.304348 \\
Market Return (Rm) & 693999 & 0.000195 & 0.000412 & 0 & 0.0074046 \\
Volume (V) & 693999 & 582822.5 & 3832688 & 1 & $3.90 \mathrm{E}+08$ \\
\hline
\end{tabular}
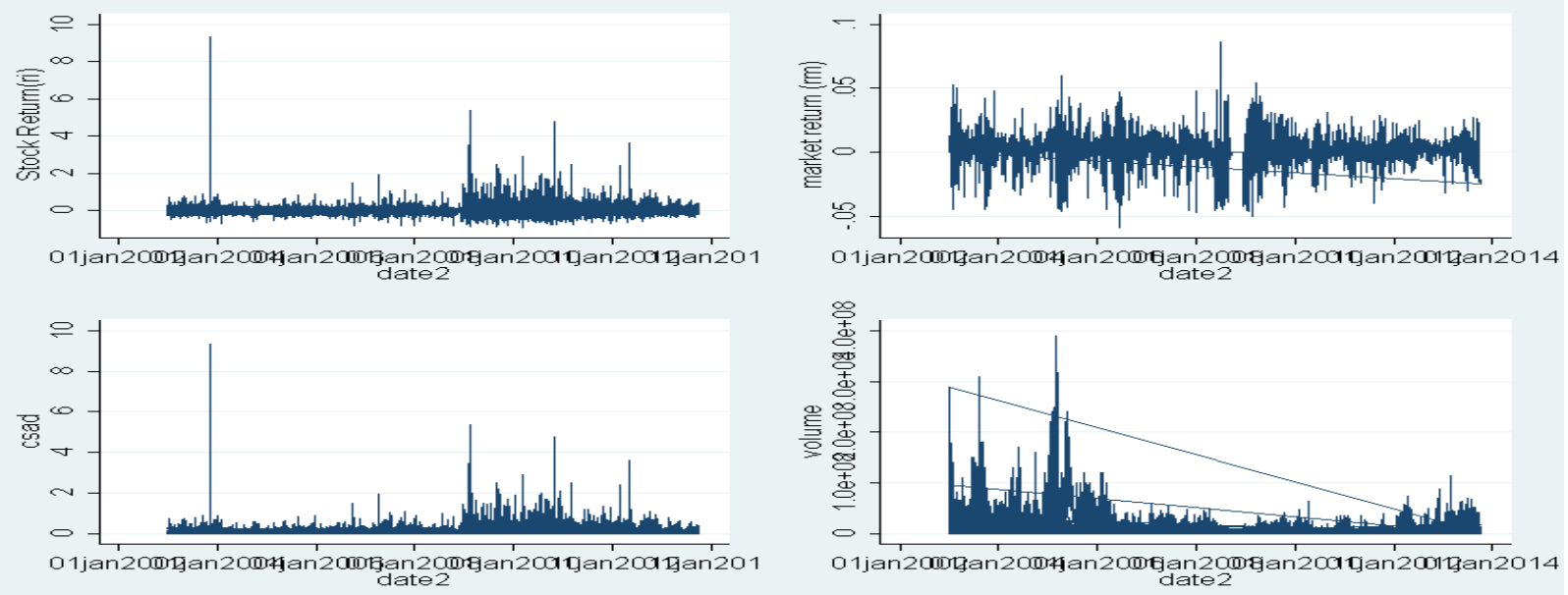

Figure-2: Graph of stock return (Ri), Market return (Rm), volume and CSAD

\subsection{Herding Results}

The equation II enables to detect herd behavior in Karachi Stock Exchange (KSE). In this equation, Cross Section Absolute Deviation (CSAD) is taken as dependent variable while absolute market returns (absrm) and market return squared $\left(\mathrm{R}_{\mathrm{mit}}^{2}\right)$ are independent variable. It is anticipated that a non- linear relationship will exist between return dispersion (CSAD) and market return squared $\left(\mathrm{R}_{\mathrm{m}, \mathrm{t}}^{2}\right)$ under abnormal conditions or market stress. This is due to fact that under abnormal conditions or market stress majority of the investors tries to follow the market and therefore return dispersion reduces. If $\gamma_{2}$ become significantly negative, it will be an indication of herding behavior. On the other hand, if $\gamma_{2}$ become insignificant or positive, it will 
show absence of herding behavior. The results in table- 3 show that a significantly negative coefficient $\gamma_{2}$ is found during regression analysis which indicates the occurrence of herding behavior. This shows that a nonlinear negative relationship exists between CSAD and $\left(\mathrm{R}_{\mathrm{m}, \mathrm{t}}^{2}\right)$ during periods of market stress. From these results we can conclude that herding exists in Karachi Stock Exchange (KSE) during the sample period 2003-2013. The detailed results are reported in table 3.

Table 3: HerdingResults

\begin{tabular}{lcccl}
\hline Statistics & $\gamma_{0}$ & $\gamma_{1}$ & $\gamma_{2}$ & $\overline{\boldsymbol{R}}$ \\
\hline Coeffiecient & 0.018 & 0.642 & -3.79 & 0.0128 \\
& $(194.39)^{* * *}$ & $(48.77)^{* * *}$ & $(-12.76)^{* * *}$ & \\
\hline
\end{tabular}

CSAD is dependent variable. Above table shows results of the equation (ii). $\mathrm{R}^{2}$ is the adjusted $\mathrm{R}^{2}$. t-statistics are shown in parentheses. Significance at $1 \%$ levels is shown as ***

These results are compared with other who used same CCK measure. Chang, Cheng and Khorana, (2000) found mixed results and reported that herding in the developed markets like Hong Kong and US did not exist and there was only some evidence ofherding in Japan. However in emerging stock exchanges like Taiwan and South Korea, they found existence of herding. As Karachi Stock Exchange is an emerging stock market therefore, to that extent, these results are consistent with their results. These results are consistent with those reported by Chiang, Li and Tan, (2010); Tan, Chiang, Mason and Nelling, (2008) that herd behavior exist in the Chinese market. Chiang, Li and Tan, (2010) found herding behavior in A-share markets. Tan, Chiang, Mason, and Nelling, (2008) found herding behavior in dual-listed B-shares in the Chinese equity market. These results are in contrast with Demirer and Kutan, (2006) who studied daily returns of 375 companies and were unable to find herding.

\subsection{Herding Results Under Up and Down Market}

In the literature review, it is a clear consensus that herding behavior may be different under up and down market conditions. Generally, investors buy more stock during the bull market. On 
the other hand many studies claimed that, the herd behavior is more prominent during falling market due to the fact that investors follow the market when it is falling. The results in table 4 indicate that during the sample period $\gamma_{3}$ and $\gamma_{4}$ are negative and statistically significant. Therefore, the results show that herd behavior exist in both bullish and bearish markets..

Table 4: Herding results under up and down market

\begin{tabular}{lllllll}
\hline Statistics & $\gamma_{0}$ & $\gamma_{1}$ & $\gamma_{2}$ & $\gamma_{3}$ & $\gamma_{4}$ & $\overline{\boldsymbol{K}}$ \\
\hline Coeffiecient & 0.017 & 0.67 & -0.61 & -3.53 & -3.93 & 0.0129 \\
& $(192.74)^{* * *}$ & $(48.13)^{* * *}$ & $(-33.65)^{* * *}$ & $(-10.46)^{* * * *}$ & $(-8.71)^{* * *}$ & \\
\hline \multicolumn{2}{l}{ Above table shows results of theequation (iv). $\mathrm{R}^{2}$ is the adjusted $\mathrm{R}^{2}$. t-statistics are shown in parentheses. } \\
\multicolumn{3}{l}{ Statistical significance at $1 \%$ levels is shown as $* * *$}
\end{tabular}

These results are contradicted with Chang, Cheng and Khorana, (2000) in developed (US, Hong Kong and Japan) and consistent in developing markets (Taiwan and South Korea). They reported that the return dispersion is more in bullish market as compared to bearish market. These results are also consistent with Tan et al. (2008) and partially consistent as reported by Chiang, Liand Tan, (2010), the former reported herding in both under bullish and bearish markets while the later found herding in only A- share market under both bullish and bearish markets and B-share market investors herd only in bearish market.

\subsection{Quantile Regression Analysis Results}

The study uses Least Squares Method (OLS) of regression to detect herding behavior under both normal and abnormal conditions. OLS method considered the mean as a measure of location and does not consider the tail information of return distribution. Therefore, the quantile regression method is used to consider different curves of independent variables against each quantile of dependent variable i.e CSAD. Table 5 presents the estimated results for using the quantile regression method. The results show that $\gamma_{2}$ is statistically significant and negative at the 
lower quantiles $(\tau=10 \%, 25 \%)$. However, analysis does not find herding behavior in upper quantiles $(\tau=75 \%, 90 \%)$.

Therefore, a conclusion can be draw that herding exists in lower quantiles but did not exist in upper quartiles during the sample period. This may be due to herd behavior by the investors for the return dispersions at the lower tail of the return distribution. Therefore, during market stress, herding occur in lower quantiles. These results are consistent with Chiang, Li and Tan, (2010) results indicate that herding exists in the median and lower quantiles of the stock return dispersions in Chinese aggregate stock market while in sub groups they found mixed results. The detailed results are reported in table 5 .

Table 5: Quantile Regression results

\begin{tabular}{lllll}
\hline Quantile & $\gamma_{0}$ & $\gamma_{1}$ & $\gamma_{2}$ & Pseudo $\mathbf{R}^{2}$ \\
\hline$\tau=10 \%$ & 0.00009 & .64 & -12.28 & 0.0592 \\
& $(23.48)^{* * *}$ & $(1151.39)^{* * *}$ & $(-998.72)^{* * *}$ & \\
$\tau=25 \%$ & -.0005 & 1.12 & -17.31 & .1122 \\
& $(-169.54)^{* * *}$ & $(9259.44)^{* * *}$ & $(-5933.67)^{* * *}$ & \\
$\tau=50 \%$ & 0.001 & .912 & 1.38 & 0.0937 \\
& $(183.05)^{* * *}$ & $(995.89)^{* * *}$ & $(61.62)^{* * *}$ & \\
$\tau=75 \%$ & 0.023 & 0.082 & 8.93 & 0.0251 \\
& $(481.88)^{* * *}$ & $(12.17)^{* * *}$ & $(54.24)^{* * *}$ & \\
$\tau=90 \%$ & 0.048 & 0.31 & 1.53 & 0.0033 \\
& $(320.62)^{* * *}$ & $(14.65)^{* * *}$ & $(14.65)^{* * *}$ & \\
\hline
\end{tabular}

Above table shows results of the different quantiles equation (ii). $\mathrm{R}^{2}$ is the adjusted $\mathrm{R}^{2}$. t-statistics are shown in parentheses. Statistical significance at $5 \%$ levels is shown as $* * *$

\subsection{Comparison of Results of OLS and Quantiles Regression}

Results in Table 5 show that the estimated coefficients and significance levels differ with the quantile levels. The comparison of results between quantile regression and conventional least squares method is necessary to analyze the difference in the two methodologies. The results of conventional least squares method show that the coefficients on $\gamma_{2}$ are significant and negative for the sample period. The results of quantiles regression analysis show that herding exists during 2003-2011 in the lower ( $\tau=10 \%, 25 \%)$ quantiles but not in upper ( $\tau=75 \%, 90 \%)$ quantiles. 
According to Chiang, Li and Tan, (2010), this difference in results in two methodologies is due to the difference in approaches of these methodologies. The OLS method considers the mean as a measure of location while the quantile regression method considers different regression curves against each quantile dependent variable i.e. conditional distribution of the return dispersion. Therefore, the quantile regression method is superior in analyzing the relationship between return dispersions (dependent variable) and market returns (independent variables). Our results also confirm this and show that herding is more visible at the lower quantiles of the return dispersions. This is due to the fact that the quantiles regression analysis is robust in finding existence of outlier.

Our results in median i.e. $50 \%$ are different from OLS method which is due to skewness of data. Another important fact is that a non- linear relationship will exist between return dispersion $(\mathrm{CSAD})$ and market return squared $\left(\mathbb{R}_{\mathrm{m}, t}^{2}\right)$ under abnormal conditions or market stress. This is due to fact that under abnormal conditions or market stress majority of the investors tries to follow the market and therefore return dispersion reduces. Therefore, herding behavior is more evident in lower tail of stock return or extreme of stock return.

\subsection{Quantile Regression Analysis Results under Up and Down Market}

Table 6 presents the estimated results for full period using the quantile regression method under up and down markets. The result show that both $\gamma_{3}$ and $\gamma_{4}$ are statistically significant and negative at the lower quantiles $(\tau=10 \%, 25 \%)$ and extreme upper quantiles $(\tau=90 \%$,). However, analysis did not find herding behavior in median $(\tau=50 \%)$ and upper quantiles $(\tau=75 \%)$ under both up and down market conditions. Interestingly, analysis finds herding behavior in upper quantiles $(\tau=90 \%)$ under both up $\left(\gamma_{3)}\right.$ and down $\left(\gamma_{4}\right)$ markets. 
These results deviate from previous quantiles regression analysis under normal conditions where herding evidence found in lower quantiles $(10 \%, 25 \%)$ while there is no evidence of it in upper quantiles (75\% and $90 \%)$. However, this deviation in results may be due to the fact that under extreme up and down conditions in the market herding may be more likely to happen. Therefore, there is herding evidence at $90 \%$ quantiles of return dispersion. Therefore, a general hypothesis may be prepared that herding exists in lower and extreme upper quantiles $(10 \%, 25 \%$, and $90 \%$ ) but does not exist in $75 \%$ quantiles during the sample period. This may be due to herd behavior by the investors for the return dispersions at the lower tail and extreme upper quantiles of the return distribution. The result show that both $\gamma_{3}$ and $\gamma_{4}$ are statistically significant but positive at $75 \%$ which shows that at this quantile, investors show rational behavior and act independently. This is due to fact that under normal conditions majority of the investors tries to act independently and therefore return dispersion increases due to which both $\gamma_{3}$ and $\gamma_{4}$ are positive. The results slightly differ from Chiang, Li and Tan, (2010) results where they found herding behavior in lower and median quantiles only in B-share investors. The detailed results are reported in table 6 .

Table 6: Quantile Regression results under Up and Down Market

\begin{tabular}{lllllll}
\hline Quantile & $\gamma_{0}$ & $\gamma_{1}$ & $\gamma_{2}$ & $\gamma_{3}$ & $\gamma_{4}$ & Pseudo R $^{2}$ \\
\hline$\tau=10 \%$ & .00009 & .645 & -.6356 & -12.5006 & -12.078 & 0.0592 \\
& $(23.64)^{* * *}$ & $(1115.76)^{* * *}$ & $(-805.91)^{* * *}$ & $(-1006.55)^{* * *}$ & $(-591.33)^{* * *}$ & \\
$\tau=25 \%$ & -0.0001 & 1.10 & -1.136 & -14.099 & -19.62 & 0.1132 \\
& $(-181.05)^{* * *}$ & $(9739.52)^{* * *}$ & $(-7472.78)^{* * *}$ & $(-5063.04)^{* * *}$ & $(-4623.07)^{* * *}$ & \\
$\tau=50 \%$ & .001 & .92 & -.90 & 1.24 & 1.46 & .0937 \\
& $(343.47)^{* * *}$ & $(1735.77)^{* * *}$ & $(-1359.20)^{* * *}$ & $(92.27)^{* * *}$ & $(81.02)^{* * *}$ & \\
$\tau=75 \%$ & .022 & .235 & .081 & 5.79 & 12.75 & .0257 \\
& $(1519.29)^{* * *}$ & $(104.6)^{* * *}$ & $(27.03)^{* * *}$ & $(102.63)^{* * *}$ & $(154.01)^{* * *}$ & \\
$\tau=90 \%$ & .04 & .42 & -.35 & .23 & -2.85 & .0036 \\
& $(347.59)^{* * *}$ & $(20.60)^{* * *}$ & $(-13.01)^{* * *}$ & $(.046)$ & $(-3.84)^{* * *}$ & \\
\hline
\end{tabular}

$\mathrm{R}^{2}$ is the adjusted $\mathrm{R}^{2}$. Above table shows results of the at different quantiles of equation (iv). t-statistics are shown in parentheses. Statistical significance at $1 \%, 5 \%$ and $10 \%$ levels is shown as $* * *, * *$, and * respectively.

\subsection{Comparison of Results of OLS and Quantiles Regression under Bullish (Up) and}

\section{Bearish (Down) Market}


The results in Table 6 show different estimated coefficients at different quantile levels. The comparison of results between quantile regression and conventional least squares method under bullish and bearish markets is necessary to analyze differences in the two methodologies. Conventional least squares method under bullish and bearish markets find herding both under bullish and bearish markets while we find different results of herding during the sample period in the lower (10\% and $25 \%)$ and extreme upper (90\%) quantiles and did not find the existence of herding in the median and $75 \%$ quantiles.

\section{Conclusion and Recommendations}

This paper studies the herd behavior of investors in the Karachi Stock Exchange (KSE). Daily data from 2003- Sep 2013 is used for this analysis. The regression results show that investors in the sample period (2003-2013) display herding behavior. The study also examines herding under bullish (up) and bearish (down) market conditions. The results show herding evidence in both bullish and bearish markets.

This study further tests the herding equation by using a quantile regression model, which is superior to ordinary least square (OLS) method and uses different quantiles of the return dispersion. The results of quantile regression show that herd behavior is more dominant in the lower tail of the dispersion of return in the sample period. This is due to fact that when the market is falling, uncertainty increases and investors try to follow other participants and the gap between dispersion of return and market return reduces. When quantile regression is used in bullish and bearish markets herding exists under both conditions in the lower quantiles $(10 \% \&$ $25 \%$ ) and at extreme upper quantile (90\%). These results depict that herding exist during extreme market conditions in the Karachi stock exchange (KSE). This show that as uncertainty increases, investors who lack clear market signals and fundamentals try to avoid acting 
independently. Therefore, investors try to follow other investors giving rise to herd behavior.

This may be due to low trading volumes and elimination of irrational small investors during this period.

These results have significance for both policy makers and investors. The herding in the stock market is due to the imperfection of the Karachi Stock Market and its regulator should take action by introducing reforms and strict regulations for efficient control of the market. The following step should be taken to avoid herding in KSE in future.

- Research and development activities should be promoted to provide small investors with more knowledge and understanding of capital markets.

- Free training, seminars and workshops should be organized to enhance technical expertise of small investors

- Clear information should be timely provided to all investors and regulations should be made to disclose all relevant information of to all stakeholder.

- Small investors should be protected from speculative trading by big investors through implementation of strict rules and regulations.

\section{References}

Amirat, A., \& Bouri, A. (2009). Modeling Informational Cascade Via Behavior Biases. Global Economy \& Finance Journal, Vol. 2 (No. 2), 81-103.

Avery, C., \& Zemsky, P. (1998). Multidimensional Uncertainty and Herd Behavior in Financial Markets. The American Economic Review, Vol. 88 (No. 4), 724-748.

Banerjee, A. V. (1992). A Simple Model of Herd Behavior. The Quarterly Journal of Economics, Vol. 107 ( No. 3), 797-817.

Barnes, M. L., \& Hughes, A. W. (2002). A quantile regression analysis of the cross section of stock market returns. Working Papers No 02-2 .

Bikhchandani, S., \& Sharma, S. (2001). Herd Behavior in Financial Markets. IMF Staff Papers, Vol. 47 ( No. 3), 279-310. 
Bikhchandani, S., Hirshleifer, D., \& Welch, I. (1992). A Theory of Fads, Fashion, Custom, and Cultural Change as Informational Cascades. The Journal of Political Economy, Vol. 100 (No. 5), 992-1026.

Chen, G., Rui, O. M., \& Xu, Y. (2004). When Will Investors Herd? -Evidence from the Chinese Stock Markets. Unpublished, 1-39.

Chiang, T. C., Li, J., \& Tan, L. (2010). Empirical investigation of herding behavior in Chinese stock markets: Evidence from quantile regression analysis. Global Finance Journal , $111-124$.

Demirer, R., Kutan, A. M., \& Chen, C. D. (2010). Do investors herd in emerging stock markets?: Evidence from the Taiwanese market. Journal of Economic Behavior \& Organization, Vol 76 ( Issue 2), 283-295.

Devenow, A., \& Welch, I. (1996). Rational herding in financial economics. European Economic Review , 40, 603-615.

Dilawar, I. (2011, October 19). Saudis to abandon HUBCO, current account deficit widens. Daily Pakistan Today .

Economic Survey of Pakistan. (2011-2012). Economic Survey of Pakistan. Islamabad: Ministry of Finance.

Economo, F., Kostakis, A., \& Philippas, N. (2010). An Examination of Herd Behaviour in four Mediterranean Stock Markets. Global Imbalances, Financial Institutions, and Reforms in the Post-Crisis Era, European Economics and Finance Society, (pp. 511-539).

Grinblatt, M., Titman, S., \& Wermers, R. (1995). Momentum Investment Strategies, Portfolio Performance, and Herding: A Study of Mutual Fund Behavior. The American Economic Review, Vol. 85 (No. 5), 1088-1105.

Holmes, P., Kallinterakis, V., \& Ferreira, M. L. (2011). Herding in a Concentrated Market:a Question of Intent. European Financial Management .

Khoshsirat, M., \& Salari, M. (2011). A Study on Behavioral Finance in Tehran Stock Exchange:Examination of Herd Formation. European Journal of Economics, Finance and Administrative Sciences, Issue 32, 167-183.

Koenker, R. (2004). Quantile regression for longitudinal data. Journal of Multivariate Analysis, Elsevier, vol. 91(1), pages 74-89.

Lakonishok, J., Shleifer, A., \& Vishny, R. W. (1992). The impact of institutional trading on stock prices. Journal of Financial Economics, 31, 13-43. 
Nofsinger, J. R., \& Sias, R. W. (1999). Herding and Feedback Trading by Institutional and Individual Investors. The Journal of Finance, Vol. 54 (No. 6), 2263-2295.

Park, B. J. (2010). Surprising information, the MDH, and the relationship between volatility and trading volume. Journal of Financial Markets, Volume 13 (Issue 3), 344-366.

Rashid, A., \& Husain, F. (2009). Testing the Weak Form Efficiency in Pakistan's Equity, Badla and Money Markets. Munich Personal RePEc Archive, Online at http://mpra.ub.unimuenchen.de/22285/.

Sias, R. W. (2004). Institutional Herding. The Review of Financial Studies, Vol. 17 ( No. 1), 165206.

Smith, N. (2011, September 12). Herding and Speculation in Experimental Asset Markets. Unpublished.

Szyszka, A. (2010). Behavioral Anatomy of the Financial Crisis. Journal of CENTRUM Cathedra, 121-135.

Tan, L., Chiang, T. C., Mason, J., \& Nelling, E. (2008). Herding behavior in Chinese stock markets: An examination of A and B shares. Pacific-Basin Finance Journal, 16, , 61-77.

Walter, A., \& Weber, F. M. (2006). Herding in the German Mutual Fund Industry. European Financial Management, Vol. 12 (No. 3), 375-406.

Wang, Y. (1993). Near-Rational Behaviour and Financial Market Fluctuations. The Economic Journal, Vol. 103 ( No. 421), 1462-1478. 